\title{
Quality Assurance Audit of Digital Intraoral Periapical Radiographs at the Undergraduate Dental Clinics
}

\author{
Muhammad Qasim Javed ${ }^{1}$, Shaul Hameed Kolarkodi ${ }^{2}$, Arham Riaz ${ }^{3}$ and Shazia Nawabi ${ }^{4}$ \\ ${ }^{1}$ Department of Conservative Dental Sciences and Endodontics, College of Dentistry, Qassim University, Saudi Arabia \\ ${ }^{2}$ Department of Oral and Maxillofacial Radiology, College of Dentistry, Qassim University, Saudi Arabia \\ ${ }^{3}$ Academy of Continuing Health Education and Research, Islamabad, Pakistan \\ ${ }^{4}$ Department of Prosthetic Dental Sciences, College of Dentistry, Qassim University, Saudi Arabia
}

\begin{abstract}
Objective: To assess the quality of digital intraoral periapical radiographs by investigating the percentage of radiographic images that satisfied the good quality standards.

Study Design: An audit.

Place and Duration of Study: Undergraduate Dental Clinics, Qassim University College of Dentistry, Saudi Arabia, from April to September 2018.

Methodology: This standard-based audit was conducted at the clinics of undergraduate dental school. A total of 506 intraoral periapical radiographs taken by dental students were graded, according to the standards set by Health Protection Agency, by two evaluators after the necessary calibration to reduce the inter-evaluator differences. In addition to the grading of radiographs, the documentation of errors like coning off, foreshortening/elongation, contact overlap, poor contrast, and image blurring was done. The data analysis was carried out with Microsoft excel software by utilising simple descriptive statistics.

Results: Out of the 506 digital periapical radiographs, 231 (45.7\%) radiographs were categorised as Grade 1, 190 (37.6\%) radiographs were categorised as Grade 2, and 85 (16.7\%) radiographs were categorised as Grade 3, requiring a repeat radiograph; and were diagnostically unacceptable. Considering the aforementioned results, the findings of the first cycle fell short of the required standards.

Conclusion: According to the results of the quality assurance audit, the radiographs were below the standards set by the Health Protection Agency. Recommendations were made for improvement measures in the radiology department, and reaudit was planned after one year.
\end{abstract}

Key Words: Quality assurance, ALARA, Radiation protection, Audit, Digital dental radiography.

How to cite this article: Javed MQ, Kolarkodi SH, Riaz A, Nawabi S. Quality Assurance Audit of Digital Intraoral Periapical Radiographs at the Undergraduate Dental Clinics. J Coll Physicians Surg Pak 2020; 30(12):1339-1342.

\section{INTRODUCTION}

The radiographic examination is the cornerstone of oral diagnosis and treatment planning. Nevertheless, even the minimal dose of ionizing radiation carries the potential risk of causing unavoidable stochastic effects. ${ }^{1}$ Therefore, it is important to justify the prescription of each radiograph for preventing the harmful effects of radiations. ${ }^{1}$

Correspondence to: Dr. Muhammad Qasim Javed, Department of Conservative Dental Sciences and Endodontics, College of Dentistry, Qassim University, Saudi Arabia. E-mail: qasim javed83@yahoo.com

Received: March 14, 2020; Revised: May 19, 2020;

Accepted: June 01, 2020

DOI: https://doi.org/10.29271/jcpsp.2020.12.1339
The 'Ionizing Radiation (Medical Exposure) Regulations'² and 'Ionizing Radiation Regulations $1999,{ }^{3}$ underscore the significance of introducing the quality assurance (QA) programmes in clinics. QA is imperative for achieving and maintaining good dental practice. Moreover, QA saves time, cost, and ensures radiation protection for the patients by reducing unnecessary radiation exposure because of repeat radiographs. ${ }^{4,5}$ The three constitutional pillars of radiation protection are: (a) justification, (b) dose optimisation, and (c) dose limitation. Hence, the goal of radiographic examination should be to accomplish diagnostic efficacy, while keeping the radiation exposure to the patients and healthcare professionals, as low as reasonably practicable (ALARP) ${ }^{6,7}$ Institutive actions to accomplish this include utilisation of rectangular collimation with the provision of lead aprons for the patients and to conduct the regular radiographic audit. ${ }^{8,9}$ The radiographic audit is a quality improvement mechanism that aims to enhance patient care and outcome by systematically reviewing the radiographs taken at 
practice and comparing them with the standard criteria. ${ }^{10}$ Considering this, the current radiographic audit will help in localising the areas where the action is required followed by the implementation of change. ${ }^{10}$ Moreover, the audit intends to ensure that dental practitioners at the clinics consistently achieve acceptable oral radiographs, with adequate diagnostic information. ${ }^{11}$

The aim of this study was to assess the quality of digital intraoral periapical radiographs (IOPA) by investigating the percentage of radiographic images that satisfied the good quality standards, and identify the most common errors of IOPA radiographs.

\section{METHODOLOGY}

The first cycle of the radiographic audit was conducted the Dental Clinics of Undergraduate Dental College, Saudi Arabia. The approval was acquired from the Ethics Committee of Qassim University College of Dentistry (ST/50/2018). The digital intraoral periapical radiographs were obtained by using Sizes 1 and 2 phosphor storage plate (PSP) sensors (Soredex ${ }^{\mathrm{Tm}}$ Digora $^{\mathrm{TM}}$ Optime). Both the bisecting angle and paralleling techniques were utilised. The receptor holders (Dentsply- Rinn Corp) were used in the paralleling technique. The quality of the radiographs was assessed by using the grading system developed by the Health Protection Agency (HPA) (Table I). ${ }^{12}$ The periapical radiographs that provided a sharp image of the crowns, roots, and $3 \mathrm{~mm}$ periapical area of the tooth in question and at least one tooth on either side of it were classified as Grade 1. Moreover, the radiographic errors in the intraoral periapical radiographs were noted. The presentstandards at the undergraduate dental clinics were compared with the standards set by HPA. ${ }^{1}$ Subsequently, for improving the current quality standards of periapical radiographs, recommendations were given.

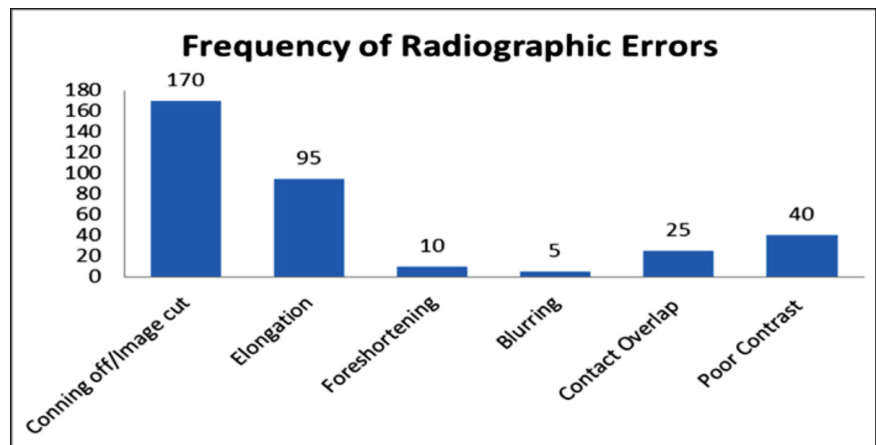

Figure 1: Bar chart exhibiting the frequency of individual errors noted in digital periapical radiographs categorised as of Grade 2 or Grade 3.

The 506 digital periapical radiographs that were taken over six months, from April to September 2018, were included in the current audit. Conversely, the IOPA radiographs taken before April 2018 were excluded from the study. To eliminate inter-evaluator bias, evaluators' calibration was done. Initially, 15 IOPA radiographs that were not included in the audit were jointly assessed by two evaluators, both with clinical experience of more than five years. These evaluators graded each film according to the grading system developed by HPA. ${ }^{12}$ The 'visible target area' meant whether or not the radiographs exhibited the complete tooth in addition to minimal $2 \mathrm{~mm}$ area beyond the tooth apex; inability to fulfil this condition would require the radiograph retake. Subsequently, after calibration, the assessment of the data was accomplished by both evaluators independently by using a standardised form. In addition to the grading of radiographs, the documentation of errors like coning off/image cut, foreshortening/elongation, contact overlap, poor contrast, and image blurring was done. Moreover, the labelling and filing of the images were also noted. The data analysis was carried out with Microsoft excel software by utilising simple descriptive statistics.

Table I: The grading system set by the Health Protection Agency (HPA). ${ }^{12}$
\begin{tabular}{|l|l|l|}
\hline Rating & Quality control & Target \\
\hline 1 & $\begin{array}{l}\text { Excellent- no errors of processing or } \\
\text { positioning or exposure }\end{array}$ & $\begin{array}{l}\text { Not less than } \\
70 \%\end{array}$ \\
\hline 2 & $\begin{array}{l}\text { Acceptable- some processing errors, } \\
\text { exposure or positioning but which still } \\
\text { allow diagnostic information to be } \\
\text { obtained }\end{array}$ & $\begin{array}{l}\text { Not greater } \\
\text { than } 20 \%\end{array}$ \\
\hline 3 & $\begin{array}{l}\text { Unacceptable- errors render the film } \\
\text { diagnostically useless }\end{array}$ & $\begin{array}{l}\text { Not greater } \\
\text { than } 10 \%\end{array}$ \\
\hline
\end{tabular}

Table II: Results of the first cycle of data collection for the digital radiographs, as compared to the target percentages.

\begin{tabular}{|l|l|c|}
\hline & \multicolumn{2}{|c|}{ Percentage \% (n) } \\
\hline Grading & HPA standard & $\begin{array}{r}\text { Digital intraoral periapical } \\
\text { radiographs }\end{array}$ \\
\hline Grade 1 & Not less than 70\% & $45.7 \%$ \\
\hline Grade 2 & Not more than 20\% & $37.6 \%$ \\
\hline Grade 3 & Not more than 10\% & $16.7 \%$ \\
\hline
\end{tabular}

\section{RESULTS}

A total of 506 digital intraoral periapical radiographs were assessed. All the radiographs were stored in correct digital files of the respective patients. Out of the 506 periapical radiographs, 231 (45.7\%) IOPA radiographs were categorised as Grade 1, 190 (37.6\%) IOPA radiographs were categorised as Grade 2 and 85 (16.7\%) IOPA radiographs were categorised as Grade 3 (Table II). Grade 3 radiographs had unacceptable errors that render the films diagnostically unacceptable. Hence, requiring repeat radiograph. Collectively, 345 radiographic errors were noted in the 54.3\% IOPA radiographs (Grade 2 and 3 ). The most common (49.3\%) radiographic error was coning off/image cut. The second most frequent error $(27.5 \%)$ was image elongation. On the other hand, the least common error $(1.4 \%)$ was the blurring of the radiographic images. Figure 1 is depicting the frequency of various radiographic errors in the digital IOPAradiographs.

\section{DISCUSSION}

The results of the clinical audit suggested that the quality of PSP IOPA digital radiographs taken by the undergraduate dental students fell below the standard set by HPA ${ }^{12}$ and improvement is needed to yield the highest quality of the information in intraoral periapical radiographs. More than half of 
the IOPA radiographs taken were categorised as Grade 2 and Grade 3. HPA guidelines state that Grade 3 radiographs should not be more than $10 \%$. However, $16.7 \%$ IOPA radiographs in the current audit were classified as Grade 3 that was outside the HPA guideline target. The outcome of the current audit was comparable with the findings of Salami and colleagues, ${ }^{13}$ where $14 \%$ of the radiographs were categorised as Grade 3 . On the other hand, the studies conducted on the Canadian dental hygiene students ${ }^{14}$ and undergraduate dental students in America ${ }^{15}$ reported that $0.8 \%$ and $1.1 \%$ of PSP digital IOPA radiographs were repeated, respectively. The information obtained from the current audit highlights the need for further training to enable the students to effectively use the PSP digital imaging technique. Videos demonstrating the particular techniques and tips can be used for improving the fundamental skills of radiography. ${ }^{15}$

The most prevalent radiographic error at $49.3 \%$ was associated with the positioning error of tube head that led to coning off on the IOPA radiographic images. The finding was in contrast with the results reported by Senior et al. ${ }^{15}$ where $14 \%$ of the PSP IOPA imaging errors were attributed to the coning off. Next, the image foreshortening/elongation and contact overlapping were collectively accounted for $37.7 \%$ errors, which were the result of incorrect vertical and horizontal beam angulation, respectively. Conversely, the previous study ${ }^{16}$ reported the prevalence of errors due to incorrect vertical and horizontal beam angulation at $26 \%$. Moreover, $1.4 \%$ of the errors occurred as a result of the subjects' movement during exposure of $x$-rays resulting in the blurring of the image. Consequently, the diagnostic utility of the radiograph was affected because of the inability to assess the important anatomical structures. Alternatively, in a study by Hasan and colleagues, ${ }^{17}$ blurring accounted for $5.2 \%$ of the radiographic errors. Various preceding IOPA radiographic audits had noted the similar findings that were attributed to the incorrect $x$-ray tube, patient, or film positioning ${ }^{13,18}$ The relatively high percentage of the radiographic errors in the present audit might be because the theoretical knowledge and practical demonstrations are delivered in the second academic year; whereas, the students start clinics in the third academic year. Thus, it is of significant importance to conduct the refresher training for students in a variety of IOPA radiographic techniques ${ }^{19}$ (bisecting angle technique and paralleling technique) at the commencement of the third academic year. Likewise, the students should be optimally trained and constantly reminded to use the beam aiming devices and film holder for proper positioning of sensors. ${ }^{13}$ Rushton and Horner ${ }^{20}$ noted significant improvement in the quality of IOPA radiographs in the second audit cycle after the introduction of film holders.

Another fault noted in the radiographs was an error in exposure that resulted in poor contrast. Poor contrast was attributed to the exposure being set on too high or too low. Digital radiographs require specific exposure settings for each arch and tooth type. These instructions are needed to be followed for an acceptable outcome. To produce a radiographic image that is diagnostically acceptable, the exposure should be set at 60-70 $\mathrm{kV}$ for intraoral radiographs. ${ }^{21}$ Exposure settings that have been set higher than the required level produce a darker image while a lower setting creates a paler image. Overexposed digital IOPA can usually be corrected with software enhancements. ${ }^{21}$ Therefore, students should be able to independently operate the viewer software for image modification. This will also prevent unnecessary repeat radiographs. All the radiographs were stored to the correct patient file in this study. The major focus in oral radiography is on the teaching of the correct technique. However, the radiograph taken with the perfect positioning and exposure is useless and needs to be repeated, if it is misfiled or mislabelled. ${ }^{22}$ Therefore, the dental team members have to play their part to ensure a high clinical standard in oral radiography.

Later, for closing the audit loupe, the reasons for radiographic errors were noted. The outcome of the audit was presented to the Department of Oral Radiology and the following recommendations were made to the College Council. Firstly, the routine utilisation of the sensor holders should be reinforced with the paralleling technique, and students should be properly educated in the bisecting angle technique. Next, the students should be optimally trained, in selecting the exposure time and communicating the clear instructions to be followed by the patients during the exposure of radiographs. Subsequently, this will make the students competent in radiological practices and protection. Moreover, the digital approval of the IOPA radiographs by the instructors before taking radiographs should be reinforced. Lastly, periodic re-audit should be conducted after a year to see whether the implemented changes have yielded desired results.

\section{CONCLUSION}

According to the results of the quality assurance audit, the IOPA radiographs fell short of standards set by HPA. The issue requires immediate attention to prevent unnecessary radiation exposure for the patients and staff members as a result of retakes. Strict measures should be implemented to help reach the required standards. The dissemination of the audit results will help raise the awareness of quality issues. However, to see the extent of improvement, the second audit will be carried out in one year after the necessary measures for improvement have been implemented.

\section{ETHICAL APPROVAL:}

Ethical approval was obtained for this study from the Dental Ethics Committee of Qassim University, Saudi Arabia (ST/50/2018).

\section{PATIENTS' CONSENT:}

As the study was designed retrospectively, data was collected from clinical archive after ethical approval.

\section{CONFLICT OF INTEREST:}

Authors have no conflict of interest to declare. 


\section{AUTHORS' CONTRIBUTION:}

MQJ, AR: Design of the work, analysis of data for the work, drafting the work, and final approval of the manuscript.

$\mathrm{SN}$ : Design of the work, final review and approval of manuscript.

SHK: Drafting of the work.

\section{REFERENCES}

1. Council on Dental Materials, Instruments, and Equipment. Biological Effects of Radiation from Dental Radiography. J Am Dental Association 1982; 105(2):275-281. doi: 10.14219/jada.archive.1982.0093.

2. Government of UK. The Ionising Radiation (Medical Exposure) Regulations 2017. [Internet].2017. [Cited 20 December 2018]. Available from: http://www.legislation. gov.uk/uksi/2017/1322/pdfs/uksi_20171322_en.pdf

3. Government of UK. The Ionising Radiations Regulations 1999. [Internet].1999. [Cited 20 December 2018]. Available from: http://www.legislation.gov.uk/uksi/1999/3232/pdfs/ uksi_19993232_en.pdf

4. World Health Organization. Quality assurance in diagnostic radiology.[Internet].1980.[cited 20 December 2018. Available from:http://apps.who.int/iris/bitstream/10665/ 39095/1/9241541644.pdf

5. Ngoye WM, Motto JA, Muhogora WE. Quality control measures in tanzania: Is it done? J Med Imag Radiat Sci 2015; 46(3):S23-30. doi: 10.1016/j.jmir.2015.06.004.

6. Jabbari N, Zeinali A, Rahmatnezhad L. Patient dose from radiographic rejects/repeats in radiology centers of Urmia University of medical sciences, Iran. Health 2012; 4(2): 94-100. doi:10.4236/health.2012.42015.

7. Lindell B, Dunster HJ, Valentin J. International commission on radiological protection: History, policies and procedures. swedish radiation protection institute. SE 1998; 171:16.

8. European Commission. European Guidelines on radiation protection in dental radiology, Radiation Protection 136. [Internet].2004. [Cited 20 December 2018]. Available from: http://ec.europa.eu/energy/sites/ener/files/documents/136. pdf

9. Clark PA and Hogg P. Reject/repeat analysis and the effect prior film viewing has on a department's reject/repeat rate. Radiography 2003; 9(2):127-37. doi.org/10.1016/S10788174 (03)00036-1.

10. Patankar SS, Karjodkar FR, Sansare KP, Vora S. Audit of the quality of intraoral periapical radiograph: An institutional study. J Oral Maxillofac Radiol 2019; 7:21-4.

11. Shockledge RR, Hill FJ. A repeated criterion-based audit of radiographic usage by a paediatric dentistry unit. Int J Paediatr Dent 1998; 8(4):269-72. doi.org/10.1046/ j.1365-263x.1998.00083.x

12. National radiological protection board. Health protection agency: Guidance notes for dental practitioners on the safe use of x-ray equipment. NRPB 2001;

13. Salami A, Al Halabi M, Hussein I, Kowash M. An audit on the quality of intra-oral digital radiographs taken in a postgraduate Paediatric Dentistry setting. J Dent 2017; 1:14-7.

14. Pachêco-Pereira C, Brandelli J, Senior A. Re-exposure rates of digital intraoral images taken by undergraduate dental hygiene students. Canadian J Dent Hygiene 2017; 51(1).

15. Senior A, Winand C, Ganatra S, Lai H, Alsulfyani N, Pachêco-Pereira $C$. Digital intraoral imaging re-exposure rates of dental students. J Dent Edu 2018; 82(1):61-8. doi: 10.21815/JDE.018.011.

16. Acharya S, Pai KM, Acharya S. Repeat film analysis and its implications for quality assurance in dental radiology: An institutional case study. Contemp Clin Dent 2015; 6(3):392. doi: 10.4103/0976-237X.161898.

17. Hasan A, Naz F, Ali SA, Khan JA, Ali B. Technical errors in intra oral radiographs obtained in endodontic department of a teaching dental hospital. J Pak Dent Assoc 2019; 28(02):51.

18. Emanuel RJ, Hussain N, Sullivan MO. A retrospective audit of radiograph quality: completing the audit cycle. Quality Primary Care 2005; 13:149-52.

19. Tatapudi R. Comparison between the commonly used radiographic techniques for intra oral imaging in dentistryA questionnaire study. Int J Dent Res 2017; 5(2):157-62.

20. Rushton VE, Horner K. A comparative study of radiographic quality with five periapical techniques in general dental practice. Dent Maxillo Facial Radiol 1994; 23(1):37-45. doi: 10.1259/dmfr.23.1.8181658.

21. Okano T, Sur J. Radiation dose and protection in dentistry. Jap Dental Sci Rev 2010; 46(2):112-21. doi.org/10. 1016/ j.jdsr.2009.11.004.

22. Picture archiving and communication systems (PACS) and guidelines on diagnostic display devices (version 1.0). The royal college of radiologists 2008 . 